\title{
De esclavos a soldados de la patria: el Ejército Libertador como garante de la libertad y la ciudadanía*
}

Recibido: 11/12/2018 | Revisado: 23/04/2019 | Aceptado: 08/05/2019

DOI: 10.17230/co-herencia.16.31.3

Jorge Enrique Conde Calderón ${ }^{* *}$

jorgeconde1@mail.uniatlantico.edu.co

Resumen El reclutamiento de esclavos y libertos en las milicias, guerrillas y ejércitos conformados durante las guerras de Independencia fue un fenómeno creciente, tanto en las filas de las fuerzas realistas como en las de los patriotas. Ambos prometieron a los reclutas con ese estatus social la libertad por su servicio militar, pero el Ejército Libertador le sumó al hecho de ser personas libres la ciudadanía. Los libertos soldados, entonces, aprovecharon el contexto generado por la guerra para luchar y afianzar la libertad, la ciudadanía y otros derechos a través de memoriales y representaciones en los cuales emplearon un lenguaje revolucionario que, en ocasiones, trascendía las propuestas de los libertadores.

\section{Palabras clave:}

Esclavo, soldado liberto, patria, república, ejército, Estado.

\section{From slaves to homeland soldiers: the Liberation Army as a guarantor of freedom and citizenship}

\begin{abstract}
The conscription of slaves and the so-called libertos in the militia units, guerrillas and armies formed during the wars of independence was a growing phenomenon, both in the ranks of the royalist forces and those of the patriots. While both forces promised the conscripted exslave soldiers to free them in return for their military service, the Liberation Army additionally promised to grant their citizenship. The liberto soldiers, then, took advantage of the context generated by the war to fight and strengthen freedom, citizenship and other rights through memorials and representations in which they used a revolutionary language that, sometimes, went beyond the proposals of the liberators.
\end{abstract}

\section{Keywords:}

Slave, liberto soldier, homeland, republic, army, state.
Este artículo hace parte del proyecto de investigación "Los soldados negros en los ejércitos republicanos, Colombia 1811-1821", que cuenta con el apoyo institucional de la Universidad del Atlántico.

** Profesor titular e investigador asociado del grupo Investigaciones Históricas en Educación e Identidad Nacional, de la Universidad del Atlántico, Barranquilla, Colombia. ORCID: 0000. 0001-6244-537X 


\section{Preliminares}

El 3 de abril de 1820, el coronel José Concha se disponía a marchar hacia Cali, capital provisional de la recién creada Provincia del Cauca, de la cual había sido nombrado su primer gobernador (Archivo General de la Nación [AGN], R, H, t. 7, f. 101). Antes de salir, recibió donativos de varios ciudadanos de la ciudad de Ibagué, donde estaba organizando e instruyendo los efectivos militares de la División Sur del Ejército Libertador. Las donaciones incluían vestuario para la tropa, mantas listadas, plantas medicinales como zen y ruibarbo, alhajas de oro y plata, y dinero en efectivo. Entre los donantes se destacaba el teniente coronel ciudadano Andrés Caicedo, quien demostró un "generoso desprendimiento", ofreciendo cuatrocientos esclavos de los cuales el coronel Concha debía reclutar solo los útiles para el servicio de las armas y excluir ciento cincuenta que pertenecían al Estado colombiano (AGN, R, H, t. 7, f. 113).

El gobernador y comandante general de la provincia del Cauca no incluyó en su Diario de Operaciones el total de esclavos reclutados; sin embargo, esto no impide señalar que ese paso les permitió a estos hombres abandonar la "infame condición de siervos" y, a partir de ese momento, ser considerados libertos, más precisamente soldados libertos. Esta señal de una nueva identidad fue modificada de manera ostensible por la misma dinámica de la guerra, que dio lugar a la de soldados de la patria. Esa rápida superposición de identidades cerró su ciclo con una de mayor connotación social: la de ciudadano soldado, portador de derechos políticos.

El reclutamiento de esclavos y libertos en las milicias, guerrillas y ejércitos conformados durante las guerras de Independencia tuvo similares razones de peso e importancia en los cambios ocurridos a finales del siglo XVIII en los imperios del mundo atlántico: español, portugués, británico y francés. Y aunque los resultados no presentaron la misma forma, hacen parte de las ingentes causas sobre la controvertida relación entre el republicanismo, la revolución y la guerra (Serna, De Francesco y Miller, 2013; Gómez y Morelli, 2013).

Esa dinámica incluyó la crisis del imperio francés en el Caribe insular, cuando las acciones insurreccionales y demandas realizadas por los negros de la isla de Saint-Domingue contrastaron sobremanera 
con la lucha de los antiguos esclavos y negros libres en la isla de Guadalupe. Estos últimos se propusieron lograr mayor autonomía y obtener derechos por la asimilación jurídica dentro del sistema de la ley revolucionaria francesa. Por medio de la acción política y militar, estos rebeldes universalizaron las ideas de igualdad y libertad con las prácticas ciudadanas emergentes, dándole un nuevo significado al lenguaje de los derechos, y ayudando, así, a la abolición de la esclavitud, en 1794, en todo el imperio francés.

Aunque, en 1802, el experimento se invirtió cuando los administradores franceses combinaron emancipación con nuevas formas de coerción y exclusión -de lo cual hay que exceptuar a los rebeldes de Saint-Domingue que crearon un Haití independiente-, la cultura política del republicanismo se transformó a través de esa lucha transcultural y transatlántica por la libertad y la ciudadanía. De esta manera, los esclavos convertidos en ciudadanos ampliaron las posibilidades políticas de la Ilustración, al proporcionar un contenido nuevo y radical a la idea de los derechos universales (Dubois, 2000, pp. 90-106; 2003, pp. 281-303).

En tierra firme americana, resonó la experiencia revolucionaria y republicana de los negros del Caribe francés, entre los esclavos y los libertos que participaron en los movimientos de Independencia. En la mayor parte de los territorios americanos, las guerras transformaron las jerarquías sociales y raciales, planteando nuevos derechos de ciudadanía. Los esclavos que se incorporaron a los ejércitos revolucionarios escuchaban de sus jefes manifestaciones de una retórica liberal igualitaria, que luego empleaban para reclamar su libertad, ampliar sus derechos de ciudadanía y contribuir, de esa manera, a la lenta desaparición de la esclavitud (Morelli, 2016, pp. 83-108; Silva, 2015, pp. 571-632; Rossigno, 2013, pp. 107-130).

Los anteriores elementos ayudarán, en el presente artículo, al análisis de las actuaciones de los libertos, y la utilización política que hicieron de los nuevos estatus logrados por ser parte del Ejército Libertador; así como de la apropiación que hicieron del lenguaje sobre la libertad y la ciudadanía, y su opinión sobre la guerra de Independencia y el ejército. Es importante tener en cuenta lo planteado por Stuart Schwartz (1992, p. 21), hace más de un cuarto de siglo, sobre la recuperación de las voces de los esclavos, las cuales permitirán 
examinar también los mecanismos con los cuales el Ejército Libertador y el Estado les garantizaron a los soldados libertos tanto su libertad como la conversión en ciudadanos de la República de Colombia.

En 1810 la población esclava de Colombia sumaba 138 000, repartidos entre la Nueva Granada (70 000), Venezuela (60 000) y Quito (8000) (Restrepo, 1858, p. XIV). Aunque era un cálculo aproximado, en la Nueva Granada mostraba un aumento del 2,7 \% con relación al censo de 1778, cuando fueron contabilizados 62529 , de los cuales 18 725, o sea, el 29,95 \%, estaban asentados en Popayán (Tovar, 1994, p. 88).

El masivo reclutamiento de esclavos durante las guerras de Independencia contribuyó de manera ostensible en la erosión de la esclavitud. En 1820, el citado coronel Concha señalaba que los esclavos formaban la principal riqueza de la provincia de Popayán, pero debido al reclutamiento de estos habían cesado las labores de las minas y los trabajos en los ingenios de caña, haciéndose notable el atraso y ruina de sus habitantes, aunque no dejaban de prestar las pocas caballerías que les restaban y otros auxilios para el ejército (AGN, R, H, t. 3, f. 234). Una explicación sobre el reclutamiento tiene múltiples aristas, pero aquí solo se pretende mostrar la que hasta ellos mismos señalaban: esforzados, robustos y estimadores del don preciado de la libertad.

\section{Más allá del reclutamiento: libertad, ciudadanía y...}

El sentido de la libertad a la que aspiraban y por la cual luchaban los libertos fue diferente al proclamado por los patriotas, el cual tenía como tema central acabar con el dominio de la monarquía en la América española. Para los esclavos, la libertad estaba asociada a los ritmos de su vida cotidiana; es decir, simplemente actuar como hombres y mujeres libres de cualquier atadura social o personal. Ellos habían experimentado, durante el régimen hispánico, que cuando invocaban la expresión "libertad", sus acciones se consideraban atentados contra el orden existente y generaban grandes inquietudes entre las autoridades, las cuales buscaban apaciguarlas empleando el poder del Estado para reprimir sus reclamos individuales o colectivos. 
En 1810, esa situación tendió a modificarse ligeramente, ya que los promotores de la Independencia introdujeron innovaciones en el lenguaje, incorporando expresiones novedosas e imágenes familiares para justificar sus acciones. Estas palabras poseían una connotación política y eran parte del lenguaje de la denominada modernidad: libertad, revolución, soberanía, representación política, ciudadanía, pueblo, regeneración, que habían adquirido una nueva carga significativa en el siglo XVIII (Blanchard, 2002, pp. 499-523). Esta "centuria del hierro", como la define Jean Starobinski (1964), sería también la de la creación de la burguesía decimonónica, la de la industria de las revoluciones democráticas, en la cual los deseos de libertad cristalizaron, salieron a flote y se desmoronaron al calor de las armas. En la arena revolucionaria apareció el tricolor con su lema "libertad o muerte” y comenzó el predominio del concepto de libertad, algunas veces en forma de comportamientos abusivos, en otras ocasiones como una forma de protesta contra el despotismo.

Ahora bien, el intento por situar la modernidad en el contexto hispanoamericano resulta paradójico, por cuanto las revoluciones de Independencia fueron iniciadas por actores sociales y políticos que, en nombre de la libertad, defendían apasionadamente la esclavitud. Aunque ellos no se opusieron de manera explícita al enrolamiento militar de los esclavos, su posición favorable al mantenimiento de la esclavitud y sus reclamos, para que estos les fueran devueltos, se hicieron más fuertes a medida que se daban los primeros pasos en la construcción del orden republicano. Sin embargo, sus opiniones también generaron respuestas contundentes, tanto de los partidarios de la abolición de la esclavitud como de los soldados libertos.

El entramado social, entonces, no fue totalmente favorable para los esclavistas, ya que, con la intensificación de las luchas revolucionarios, los conceptos de libertad y lealtad a la patria adquirieron mayor importancia. En el discurso apareció una particular analogía: quien luchaba por la libertad también lo hacía contra la "esclavitud" y, simultáneamente, contra España, señalada de haber esclavizado durante tres siglos a los americanos, quienes consideraban que esa relación de dominación había impedido realizar su potencial y evitado asegurarles a los habitantes de la América española no solo la liber- 
tad, sino también la justicia, la igualdad y todos los demás derechos que había impedido cristalizar. La metáfora de la esclavitud, asociada al despotismo español, tuvo una alta aceptación en todos los niveles de la sociedad, pero tocó un acorde especialmente resonante entre los esclavos (Blanchard, 2002, pp. 500-502).

Esa clase de la sociedad hispanoamericana, esclavizada de hecho por ley, se sintió atraída por cualquier lenguaje que pregonara libertad, ya fuese del bando realista o patriota, aunque fueron los jefes del primero quienes reclutaron esclavos. El asturiano José Tomás Boves lo hizo contribuyendo con su declaración de "guerra a muerte a los blancos", a la derrota de la Primera República venezolana (Carrera, 1972). En los años siguientes, Simón Bolívar buscó obtener altos réditos de esa dolorosa experiencia declarando también la "guerra a muerte”, y se empeñó en captar la simpatía de los pardos, mulatos, negros y llaneros proclamando, el 2 de junio de 1816, la libertad de los esclavos cuya incorporación al Ejército Libertador fuera voluntaria (Vergara, 2011, pp. 47-85; Conde, 2009, p. 181).

El reclutamiento de esclavos y libertos comenzó desde el inicio del movimiento de Independencia y no fue ninguna novedad, ya que el régimen hispánico, desde finales del siglo XVII, practicó la incorporación de pardos, negros, zambos e indígenas a milicias constituidas por los vecinos para defenderse de indios hostiles o negros cimarrones. En la segunda mitad del siglo siguiente, una reforma militar reglamentó los cuerpos milicianos y les confirió fuero militar a sus reclutas. A partir de 1810, se multiplicaron los cuerpos milicianos con diferentes denominaciones: Cívicos, Patriotas, Urbanos, Voluntarios de la Guardia Nacional, Auxiliares, Defensores de la Patria, entre tantos otros. Todas estas fuerzas irregulares y el ejército de línea reclutaron esclavos y libertos a través de diversos canales: forzoso, conscripción selectiva entre los vecinos, voluntaria convocada por bando y la realizada por donativos de amos que esperaban ser recompensados con títulos militares o indemnizados por el Estado (Thibaud, 2003; Pita, 2012).

También hubo casos de esclavos que se fugaban de sus amos y aprovechaban el ambiente bélico para ingresar a las milicias, guerrillas y ejércitos, manteniendo en absoluto silencio su condición servil o presentándose con una identidad distinta. Esos hechos proporcionaron a esta clase de soldado una ventaja relativamente incompa- 
rable frente a otros reclutas, la cual demostraban en medio de la guerra encarando los combates de forma encarnizada. Para ellos, una victoria lograda tras cada batalla significaba un paso adelante en la obtención de su libertad definitiva.

La mayoría de los jefes militares tuvieron en cuenta ese atributo para considerarlos un elemento valioso en las guerras de Independencia. Esto contrastaba con la opinión de un sector de los dirigentes republicanos, para quienes el reclutamiento de esclavos podía revertirse en cualquier momento en una guerra social apoyada por la "gente de la clase de pardos y morenos". Esta idea fue convirtiéndose en un fantasma que recorría la mentalidad de esos republicanos, en ocasiones recreada con una supuesta guerra sangrienta de los pardos y morenos contra los blancos, como le comunicaba un ciudadano de la Provincia de Guayana al vicepresidente del departamento de Venezuela (AGN, PyS, t. 3, ff. 121-122). Ese ciudadano, además funcionario del gobierno provincial, aducía que el levantamiento de pardos y morenos era inminente porque el gobierno había engañado a los esclavos ofreciéndoles la libertad y luego "le han faltado" (AGN, PyS, t. 3, f. 121v).

En la realidad, ese tipo de alianzas estaba lejos de concretarse, pues los intereses sociales y políticos de pardos y mulatos, por un lado, y esclavos o libertos, por el otro, raramente coincidían. Lo que sí resultó complejo fueron las contradicciones generadas entre los dirigentes republicanos por ese tipo de reclutamiento, dando lugar, entre muchos de ellos, al surgimiento de frecuentes "dilemas negros", para usar el sugestivo título del artículo de un historiador (Izecksohn, 2010, pp. 55-74). Este fenómeno incrementó las inquietudes de algunos dirigentes republicanos, no solo por la adhesión permanente de soldados libertos al Ejército Libertador, sino también por lo que podía ocurrir en el corto plazo si estos llegaban a organizarse: "una guerra de colores". Mientras tanto, los soldados libertos actuaban sin lugar para las dudas contra todos esos supuestos, aprovechando la nueva realidad generada por la guerra para afianzar su autonomía y fusionar el conjunto de derechos heredados del régimen hispánico con los contenidos en la proclamación bolivariana de 1816 (Prado, 2014, pp. 142-156; Echeverri, 2009, pp. 45-72).

Aún más, algunos esclavos y libertos reconocieron preceptos igualitarios en esa y otras proclamas elevándolos a la categoría de docu- 
mentos fundadores, aunque incurriendo en el empleo equívoco de algunas expresiones. En particular, el concepto de ciudadanía fue utilizado con igual significado por hombres y mujeres, aunque la Constitución de Cúcuta, en 1821, establecía que esa era una condición de la cual gozaban solo los colombianos varones con ciertas calidades (Conde, 2009, pp. 72-73).

El empleo generalizado de la palabra ciudadanía permite explicar la presentación de una mujer, quien reclamaba como la "ciudadana María Rafaela Guardia, morena libre", ante el general José Francisco Bermúdez, para que evitara el castigo de su "legítimo Mario José Antonio Martínez esclavo del ciudadano Cristóbal Martínez". Este había sacado al soldado liberto del cuartel cuando las tropas bajo el mando de Bermúdez estaban en el Puerto de La Guaira, lo había despojado del uniforme y reducido a prisión en su hacienda. La "ciudadana" suplicaba que su "legítimo" regresara al servicio, ya que él quería "más bien servirle a la República que a su amo". La solicitud sería remitida al presidente de la República de Colombia, general Simón Bolívar, en Caracas, el 2 de agosto de 1821, quien ordenó el regreso inmediato del liberto al servicio de las armas (AGN, PyS, t. 16, f. 412).

Aunque esas situaciones originaron tensas relaciones entre el gobierno republicano y los propietarios de los esclavos y libertos, al final se impuso la autoridad del Estado, respaldada por la fuerza legítima del Ejército Libertador. De hecho, las decisiones eran controvertidas, pero permitieron que esclavos y libertos dieran un paso más allá de las propuestas de los libertadores, y las aplicaran a sus propias circunstancias para justificar su emancipación personal.

El 5 de agosto de 1822, en la ciudad de Pasto, recién ocupada por el Ejército Libertador, el presidente de la República, Simón Bolívar, recibió la visita del esclavo Francisco Baraona y escuchó de su propia voz la solicitud de libertad. El Libertador le dijo que se dirigiera al gobierno de la provincia para que le "impartiese la Justicia" correspondiente e, inmediatamente, le hizo entrega del pasaporte para que siguiera a la ciudad de Popayán, donde el coronel José Concha, ahora intendente, gobernador y comandante general del Departamento del 
Cauca, le entregaría su carta de libertad (AGN, R, H, t. 2, f. 566).

Lo interesante de este caso es el lenguaje empleado por Baraona en el memorial presentado al intendente y los argumentos de este último justificándole a Bolívar por qué debía concederle la libertad. El coronel Concha señalaba que el esclavo representaba ser "muy patriota", lo cual era "razón natural" para que viviera libre, se hacía merecedor de ese premio por "su patriotismo decidido desde el principio de la transformación política”, y terminaba señalando al presidente de la República como el único autorizado para concederle la libertad por cuanto el esclavo le "corresponde al Estado" (AGN, R, H, t. 2, f. 567v).

Por su parte, Baraona iniciaba su memorial reconociendo ser esclavo del rey de España, pero que "los triunfos de nuestras tropas", lo habían puesto, de hecho, en posesión de "la libertad que me dio naturaleza”. Libertad que había dejado

de existir en medio de los tiranos, y en los tristes tiempos en que se quería confundir a los hombres con las bestias. Soy colombiano, y no habiendo ley que perjudique mi solicitud, fundada en el derecho natural, en el público de gentes, y sostenida por la expresión bien manifestada del Superior Gobierno en sus disposiciones, y principios, imploro la protección de VS cuya filantropía de sentimientos es pública. VS ha sabido combatir por la Libertad en General de la Nación, y no abandonará al infeliz colombiano que reclama la particular que le toca al impartirle la Justicia distributiva que solicita (AGN, R, H, t. 2, f. 567). ${ }^{1}$

En el discurso de Baraona, ocupa un lugar importante la patria, que no solo lo "hizo libre", sino también le permitía definirse como "colombiano" y, de hecho, ciudadano y patriota por cuanto los colombianos pasaron a pertenecer ahora a algo glorioso: la patria. Esa novedad se repetía en otros contextos hispanoamericanos y estaba en plena correspondencia con la apropiación de un nuevo lenguaje político y del mensaje revolucionario (Frega, 2010).

1 Cursivas del autor. 


\section{Por el amor a la patria, y defensa del gobierno y República de Colombia}

Durante las marchas de los ejércitos milicianos, soldados, reclutas y hasta oficiales entonaban cánticos, verdaderos "himnos de gloria" (Vergara y Velasco, 1897, p. 9), que eran silenciados por los toques de las cornetas y el continuo redoblar de los tambores, los cuales anunciaban el inminente combate; entonces, disparaban o embestían al enemigo con la bayoneta, el cuchillo o el machete. En medio del fragor de la batalla y el fuego de una y otra parte, continuaba "el interesante resonar de las bandas y tambores” (Espinosa, 1932, p. 107).

¿Qué entonaba la tropa antes de entrar en combate? Cánticos de victoria para avivar el fervor patriota, pero, además, versos extraídos de las proclamas de prosa épica, cuyas frases fijaban la suerte de la guerra en manos de la tropa. Según esos textos, la soldadesca debía desempeñarse "y aprended a ser libertadores de vuestra patria", como concluía su arenga el general mulato José Padilla a bordo del navío Colombiano (AGN, FEOR, c. 193, ff. 768-769; Conde, 2011, pp. 21-27). O como iniciaba la suya el general Santander, todo un experimento de alquimia patriota que fusionaba al soldado con el ciudadano para obtener un Ejército Libertador fuerte: “SSoldados! De vuestra constancia y de vuestro valor depende la suerte de la Nueva Granada. ¡Ciudadanos! De vuestro patriotismo depende el aumento y conservación del Ejército" (Ejército de Vanguardia, 1969, pp. 11-12).

La patria pasó, entonces, de ser el lugar de nacimiento a un acto de fe que anulaba todas las formas precedentes de fidelidad. Por el fervor patriota, Colombia renació y se regeneró como República; siendo los republicanos verdaderos ciudadanos modelo de la virtud revolucionaria, y los soldados ciudadanos los que combatían contra el invasor extranjero. La guerra adquirió, de esta manera, un carácter de cruzada, y la ficción del soldado ciudadano, el de una maquinaria que funcionaba a la perfección (Schama, 1990, pp. 491-498).

¿Asimilaron los soldados libertos ese discurso sobre la patria, la república y el Ejército Libertador? Una respuesta afirmativa no admite dudas. Luego de ingresar al servicio de las armas, los esclavos se sentían libres y aceptaban su permanencia en el ejército porque eso 
les garantizaba la libertad. En los primeros días de marzo de 1820, un grupo de esclavos radicados en la ciudad de Neiva le remitieron a Bolívar, instalado en Bogotá, una solicitud de su libertad. El Libertador firmó, el 7 de ese mes, el decreto concediéndoles la petición a los veinte esclavos que rubricaban la representación y, acto seguido, los destinó al Ejército del Sur, el cual mantenía la ofensiva final contra las fuerzas realistas concentradas en la provincia de Popayán (AGN, PyS, t. 6, ff. 349-350). Los esclavos aceptaron sin objeción alguna el destino asignado, el cual les resultaba familiar, ya que eran sobrevivientes de la Expedición del Sur que, entre diciembre de 1813 y mayo de 1814, dirigió el presidente del estado de Cundinamarca, Antonio Nariño, con el objetivo de liberar esa provincia del poder realista, aunque al final terminó derrotado de forma estruendosa cerca de la ciudad de Pasto (Espinosa, 1932).

En su representación, los esclavos realizaban un recuento, "en memoria", de la forma como fueron incorporados por el general Nariño después de pasar "de las temporalidades de los exjesuitas [a] siervos del español Clemente Alguacil, y por la traslación de reconocimiento en la misma clase del distinguido ciudadano Luis Caicedo", cuyos herederos por la ejecución del censo causado los entregaron al "erario público en la época pasada de la República" (AGN, PyS, t. 6, f. 349). En medio de esas circunstancias, Nariño escogió a "los más esforzados y robustos [para que] lo siguiésemos de zapadores comprometiéndose a darnos la libertad" si eran vencidos los enemigos de Popayán (AGN, PyS, t. 6, f. 349; Clavijo, 1989, pp. 49-77).

En efecto, esos adversarios fueron vencidos y arrojados de la ciudad, y los patianos y pastusos perseguidos hasta los ejidos de su ciudad, pero una "mala dirección" perdió al ejército patriota, y a los esclavos se les incumplió sobre su libertad. Estos señalaban que "creyéndonos entonces hombres libres" reportaron haber salvado sesenta mil pesos conducidos en la caja militar y la recuperación de buena parte de los pertrechos de guerra, pero cuando regresaron a sus lugares de residencia no encontraron "estimadores del don preciado de la libertad [y] nuestra voz fue ahogada" hasta saber de los informes de los ciudadanos doctor Alejandro Osorio, José Leyva y Martín Melendro, los cuales hicieron presente que el Gobierno de Colombia era presidido por Bolívar, ese "Don de la Libertad" al cual elevamos "nuestra voz" (AGN, PyS, t. 6, ff. 349v-350). 
Las solicitudes de los libertos aceptando su permanencia en los Ejércitos de Colombia eran dirigidas a los oficiales superiores, quienes luego las remitían al presidente o vicepresidente de la República. Llama la atención que en esos documentos las impresiones plasmadas por estos señalan a antiguos amos aferrados todavía a la idea de la propiedad de personas, desconociendo que los libertos, como soldados de la patria, estaban regidos según lo dispuesto por las leyes de la República y los reglamentos militares. Por su parte, el liberto soldado tenía claro su lugar en el novedoso contexto generado por la guerra, y el campo de posibilidades que se le presentaban para actuar libremente sobre lo que deseaba y lo que no. Un ejemplo notable fue Antolino Gamarra o Antonio Altamar, reclamado por la ciudadana Francisca Castrillo por el primer nombre y, según ella, haber hecho parte de los catorce esclavos que se le fugaron luego de la emigración de su marido en 1814 (AGN, PyS, t. 16, ff. 383-385).

El reclamo de la señora Castrillo, siete años después, recorrió un camino enmarañado, porque, en principio, pidió la restitución de un esclavo llamado Antolino que militaba "en los Ejércitos de Colombia", pero las averiguaciones hechas por los oficiales encargados del caso no encontraron "el nombre del indicado". Luego, el memorial que presentó se había "perdido o traspapelado", lo cual obligó a repetir las diligencias antes practicadas. Al final, el ciudadano Felipe Guerra, yerno de Francisca, identificó a Antolino, quien en ese momento era conocido como Antonio Altamar, soldado de la segunda compañía del Batallón Granaderos. Pero el asunto no terminó con la ubicación del liberto que había adoptado un nombre diferente, pues el vicepresidente de la República, Carlos Soublette, comisionó al capitán Eustaquio Sojo para que practicara lo solicitado por Francisca: examinar la voluntad del soldado sobre si era su deseo volver al servicio de su ama. La respuesta del soldado liberto fue lacónica: "Quiero continuar en el servicio de la República” (AGN, PyS, t. 16, f. 385v).

En otro lugar, y sin pasar por el examen de su voluntad, José de los Santos Madriz, soldado del Escuadrón de Caballería del ciudadano comandante Francisco Flórez, dirigió una representación al vicepresidente Soublette, para que se le mantuviera en el "servicio de la República”, a la que había ingresado luego de escuchar que "el General Bermudes había dicho que todo esclavo que tomara las almas 
[armas] y siguiese en acción, sería libre después de ella". A partir de ese momento, decidió incorporarse a la tropa de ese general, "dentrando en acciones, y demás servicios del Estado", hasta que en la de "los dos caminos" fue capturado por las tropas enemigas y remitido con otros prisioneros a presidio. En ese lugar se presentó doña Rosalía de Madriz, su antigua ama, quien, en presencia de un oficial, le puso unos grillos y le dio doscientos azotes "hasta desmallarme en el castigo". Una vez liberado por la mediación de un teniente de caballería, quien cumplía órdenes del comandante Flores, por ser "uno de los individuos de su cuerpo defensor de la República comprometido a perder la última gota de sangre de ella”, el soldado fue categórico en señalar no querer ningún trato con doña Rosalía, porque ella "no tiene sobre mí ningún dominio" y, además, en su enrolamiento voluntario "no me llevó a mí el interés de la libertad de amo sino el amor a la Patria, y defender el gobierno y República de Colombia" (AGN, PyS, t. 16, ff. 298v-299).

En los casos de los soldados Antolino Gamarra (Antonio Altamar) y José de los Santos Madriz, las respuestas de los jefes del Estado Mayor del Ejército y del vicepresidente fueron diferentes. Las acciones de Rosalía de la Madriz se consideraron "con el mayor desagrado", e incidieron en una posible indemnización (AGN, PyS, t. 16, f. 298); mientras que el reclamo de Francisca Castrillo se aplazó para "la indemnización a esta interesada en la debida oportunidad" (AGN, PyS, t. 16, f. 386).

\section{El ejército garantiza, el Estado indemniza}

La sustracción de un soldado liberto de las filas del ejército tenía implicaciones políticas y económicas, como la negación o aplazamiento de la indemnización a que tenía derecho el propietario del esclavo. Cuando eso sucedía, los oficiales superiores y, en algunos casos, el presidente o vicepresidente de la República impartían órdenes conminando a los amos a agilizar el regreso del soldado, sustraído la mayoría de las veces con el ofrecimiento de la libertad si regresaba a su lado. Las acciones de los oficiales superiores se guiaban, entonces, por lo señalado en los reglamentos y nuevas ordenanzas militares, con lo cual intentaban garantizar los derechos y fueros de todos los 
miembros del cuerpo armado. En fin de cuentas, como le comunicó Bolívar a Santander: en "Colombia el pueblo estaba en el ejército", este era el poder real, el que actuaba, el que elegía, donde estaban los ciudadanos activos, pues, quienes estaban por fuera de ese cuerpo eran considerados ciudadanos pasivos (Bolívar, 2009, pp. 184-186).

El ejército no solo era una fuerza militar que representaba un poder social y político. También fue un difusor de principios liberales, elemento legitimador de la representación política, fundamento de la República y pilar fundamental del Estado. En algunas de esas instancias, los ciudadanos realizaban sus reclamos, peticiones y solicitudes, las cuales eran atendidas oportunamente según los términos señalados por la ley. Por ejemplo, Manuel González, "de nación africana, moreno libre", solicitaba, por su avanzada edad, la exclusión del servicio militar de su hijo José Tiburcio, quien siempre lo acompañó en el "trabajo de labranza" hasta que, animado por su "acendrado espíritu patriótico", sirvió de voluntario en los ejércitos llegando a participar en los "triunfantes campos de Carabobo". El vicepresidente general Soublette accedió a la petición y ordenó "la exclusión del servicio al individuo que se reclama” (AGN, PyS, t. 16, f. 296-297).

Los reclamos por indemnizaciones ocuparon particular atención, aunque estuvieron sujetos al cumplimiento de unos formulismos y en concordancia con las leyes de la República por tratarse, en la práctica, de un contrato verbal entre un civil y el Estado (Restrepo, 1954, p. 56). De igual manera, entre el esclavo y el Estado existió una relación contractual en la que el primero estaba obligado a cumplir un tiempo de servicio que oscilaba entre tres y seis años. A cambio, el soldado recibía comida, uniforme, bagaje y entrenamiento, un aspecto en el cual siempre tuvo cierta ventaja sobre el resto de los soldados al estar su cuerpo acondicionado a las faenas del campo y la minería y, además, por su predisposición a la subordinación (AGN, PyS, t. 1, ff. 107 y 123; R, H, t. 7, f. 96; Rabinovich, 2013, pp. 40-53).

Por consiguiente, los reclamos de los antiguos amos tenían en cuenta esos valores agregados de los libertos al momento de reclamar su indemnización, pero la solicitud debía cumplir con las formalidades establecidas por las leyes de la República. En caso contrario, el Estado consideraba inviable o negaba el pago de la indemnización, 
como sucedió con la viuda Xaviera Guerra, quien pidió la devolución de los bienes muebles, inmuebles, ganado y "un mulatico" que fueron embargados cuando emigró con su marido, pero luego que regresó, "a mi Patria", esperaba "con la mayor confianza mediante los liberales principios del gobierno [...] otorgarme esta gracia”. En esa ocasión, la respuesta fue firmada por el secretario de Hacienda, José María del Castillo, que el 17 de mayo de 1822 resolvió negar la solicitud por cuanto el gobierno "no está autorizado para hacer gracias; y que en el punto de justicia recurra al juzgado correspondiente que se le administrará" (AGN, PyS, t. 3, f. 672). Ciertamente, mercedes, fueros y gracias eran privilegios correspondientes al Antiguo Régimen y solo el rey los dispensaba, pero para el duodécimo año de la Independencia, la Constitución era ya el único remedio legal (Conde, 2017).

A casos como el anterior, se le sumaban los reclamos realizados a oficiales o funcionarios que carecían de las atribuciones judiciales para conceder la libertad de esclavos, desembolsar el dinero de la indemnización o entregar un liberto soldado, como insistió el ciudadano Andrés Vicari a Camilo Mendoza, comandante y jefe de una columna que marchaba desde Puente Nacional hacia Bogotá. El ciudadano mencionado solicitaba la entrega de su esclavo Domingo Pinzón, que iba incorporado como recluta en la columna, a lo cual el oficial respondió que no tenía "facultades para desembolsar arbitrariamente la fuerza a sus órdenes”, además, que la solicitud de Vicari era una "petición verbal" que no se correspondía con lo señalado por el Congreso de la República (AGN, PyS, t. 11, f. 225).

Por consiguiente, los ciudadanos debían tener en cuenta, durante la presentación formal de sus reclamos, las instancias judiciales en que debían radicarlos y, en últimas, el ramo de la hacienda pública que se encargaba de hacer efectivo el pago de la indemnización, en este caso el erario nacional o las cajas nacionales. Con la Ley de 19 de julio de 1821, "Sobre libertad de partos, manumisión y abolición del tráfico de esclavos", se trasladó el pago a los gobiernos provinciales, ya fuese por manumisión o indemnización de esclavos incorporados al ejército, para atender de esa manera las particularidades de cada caso. En cada cantón, se crearon fondos de manumisión, los cuales estaban vigilados por una junta integrada por el primer juez del lugar, el vicario foráneo eclesiástico de la parroquia y un tesorero 
nombrado por el gobernador de la provincia. Asimismo, los jueces fueron los únicos funcionarios con las competencias judiciales para declarar la libertad de los esclavos y esclavas, siempre y cuando la hubieran obtenido de los diferentes gobiernos republicanos en fuerza de leyes y decretos. En este capítulo, se tenía en cuenta lo actuado en esa materia por los gobiernos de la Primera República (Cuerpo de leyes de la República de Colombia, 1840, pp. 29-31).

Con la vigencia de esa ley, se liberó a la Secretaría de Hacienda de una parte de los trámites generados por los reclamos de indemnizaciones hechas por los antiguos propietarios de esclavos. De esa manera, se legisló en el caso de Olalla Buróz de Soublette que, a nombre de su madre, Josefa Antonia Tobar, reclamaba la indemnización de su esclavo, quien "obtuvo su emancipación" por haber tomado las armas de la República y, en ese momento (1825), pertenecía al Ejército Libertador. Desde Bogotá, la Secretaría de Hacienda ordenó que el pago se realizara de los fondos de manumisión en Caracas (AGN, PyS, t. 15, f. 42).

Con similar orden, se resolvió el reclamo de la viuda Ana Gertrudis Palmesano, aunque su caso adquirió el carácter de una querella judicial debido a que afirmó solo haber visto a su esclavo Vicente Luis marchar con el Batallón Rifles de la Guardia cuando ella estaba en la parroquia de Fonseca (AGN, PyS, t. 5, f. 89). Por lo tanto, Ana Gertrudis tuvo que demostrar que el esclavo era de su propiedad, tomando el caso una característica inusual por tratarse de un zambo, lo cual hacía difícil su identificación, ya que ese era un color de piel muy generalizado entre los soldados. La primera evidencia adjuntada por la reclamante fue la escritura pública de compraventa firmada entre las partes el 29 de abril de 1818, en la ciudad de Riohacha. El documento estipulaba que su primer dueño, José Vicente Cienfuego, vendió a José de Armas, difunto esposo de la querellante, el zambo heredado de su legítima madre, por la cantidad de 220 pesos.

Seis años después, la querella judicial requirió la declaración de varios testigos y la certificación de José Sardá, coronel de los Ejércitos de Colombia, gobernador y comandante de armas de la plaza y provincia de Riohacha. Este jefe militar señaló que Vicente Armas había ingresado voluntariamente en la Segunda Compañía del Batallón de Rifles de la Guardia. La viuda corroboró lo certificado por el 
gobernador diciendo que el esclavo se había fugado en 1821 y "sentó plaza de soldado en Santa Marta”, en el mencionado batallón. El mismo Sardá ordenó el pago de los fondos de manumisión a que tenía derecho la suplicante, pero con la novedad de realizar los descuentos señalados por ley (AGN, PyS, t. 5, ff. 87-91).

En efecto, el 1.o de febrero de 1822, el vicepresidente general Santander decretó, a raíz de varias dudas surgidas en la aplicación de la Ley del 21 de julio de 1821, que los gastos precisos de amanuense, papel y libros, así como las cuentas llevadas por el tesorero y otros indispensables, sería abonadas de los mismos fondos de manumisión, previa comprobación legal (Mier, 1981, pp. 47-48).

En el pasado reciente, algunas solicitudes habían sembrado esas dudas, como ocurrió con José Tomás Durán, quien reclamó el pago a cargo de las Cajas Nacionales de solo las dos terceras partes de los 200 pesos que, según él, era el valor de su esclavo Bautista, alistado en el servicio de las armas de la República. Antes, Durán había concurrido ante el ministro de la guerra, coronel Pedro Briceño Méndez, quien denegó la solicitud remitiéndola al presidente de la República, por el correspondiente vale del importe indicado de 200 pesos, pero no se presentó e insistió en el pago de las dos terceras partes, lo cual fue negado sin otra explicación (AGN, PyS, t. 16, f. 264).

Aunque los fondos de manumisión fueron los entes creados para esos pagos, las precarias finanzas de las provincias determinaron que los propietarios de esclavos dirigieran sus reclamos, en primer lugar, a las Cajas Nacionales. El Gobierno autorizaba su pago siempre y cuando el caso fuera anterior a la ley de 1821, ya que se trataba entonces de una deuda nacional. Un caso de estos fue el de María Josefa de la Torre, vecina de la ciudad de Cartagena, reclamante del esclavo Ambrosio González, quien se había fugado de su casa en agosto de 1820, tomando "partido por las tropas de República" $y$, en 1825 , se encontraba en el servicio de la escuadra y se negaba a solicitar su indemnización de los fondos del erario de la intendencia del Magdalena por cuanto al momento de la fuga del esclavo no se había expedido la mencionada ley. En consecuencia, Josefa solicitaba se le abonaran del erario nacional los 300 pesos en que se tasaba su propiedad, la cual "por su edad, robustez y agilidad son estimados en aquella plaza los de su clase" (AGN, PyS, t. 8, f. 232). 
El Estado correspondió realizando el pago a Josefa de la Torre, y también lo hizo con el ciudadano Joaquín Franco, en ambos casos por ser reconocidos como parte de la deuda nacional (AGN, PyS, t. 15, f. 343). De esa manera, el Estado cumplía sus obligaciones contractuales y el ejército garantizaba la permanencia de los soldados libertos en el servicio de las armas. Aun habiendo cumplido el tiempo de servicio, algunos libertos seguían gozando de las garantías constitucionales y la protección del Ejército Libertador. En 1821, el ciudadano José Martín Yanes se quejaba de que su esclavo Silvestre, de color y calidad pardo, quien luego de ser "miembro de las armas" con el "concepto de libre estaba asalariado, vendiendo en una tienda pública”. Yanes decía sentirse preocupado porque Silvestre lo miraba de manera altanera y un espíritu lleno de orgullo, mientras que el alcalde de la localidad y el jefe militar de la plaza no actuaban para "traerlo a mi dominio". Al final, sus clamores se fueron apagando sin respuesta oficial (AGN, PyS, t. 16, f. 272).

\section{A manera de conclusión: ciudadanía e igualdad política}

El contexto de las guerras de Independencia y el reclutamiento de esclavos en los ejércitos permitieron a estos actores alcanzar la libertad y convertirse en ciudadanos de la República. Con la ciudadanía, surgió la forma más elemental de la igualdad política, la cual marca la entrada definitiva en el mundo de los individuos, el de un hombre, una voz o, para resumirlo con el sugestivo título que acompaña la introducción del libro de Pierre Rosanvallon (1999), la más real de todas: "la Revolución de la Igualdad".

La igualdad política fue lo más artificial, pero también lo más ejemplar, fraguado en medio del calor de la lucha revolucionaria. Los libertos, como ciudadanos soldados, la utilizaron para sus reclamos y peticiones, en los cuales, además, dieron señales inequívocas de la apropiación de un nuevo lenguaje político, con el empleo de expresiones como patria, República, Estado, derecho natural y de gentes. Lograr esos valores republicanos estuvo condicionado al cumplimiento de las leyes, reglamentos, ordenanzas militares y otras disposiciones gubernamentales que el Estado intentaba imponer para que 
los ciudadanos soldados acataran y cumplieran. La transgresión de esas normas y disposiciones era objeto de medidas punitivas, entre las cuales estuvo comprendido el delito de deserción.

Los soldados desertores eran sometidos a sumarias judiciales, cuyas diligencias se llevaban de manera ágil, ya que se trataba solo de la aplicación de lo establecido por los reglamentos militares en la materia. Sin embargo, hubo procesos prolongados, como el de dos desertores, que transcurrió entre 1825 y 1826. Ambos soldados, de apellido Flores y pertenecientes a la Compañía de Cazadores de un batallón en Panamá, eran acusados de desertar durante la guardia de la noche, pero sus explicaciones sobre la fuga, la denuncia de "mal trato" recibido de los cabos y las declaraciones de oficiales ocuparon más del tiempo previsto por la corte marcial (AGN, AC, t. 29, ff. 1-68). En otros casos, se combinaron la justicia ordinaria y militar para juzgar implicados en el delito de deserción, lo cual ocurrió con la causa criminal seguida en la ciudad de Neiva a tres desertores del Ejército del Sur (AGN, AC, t. 84, ff. 1-6).

Las causas criminales o cortes marciales que procesaban a los desertores fueron seguidas a todos los soldados y oficiales sin excepción. ¿Desertaban los libertos? Los expedientes consultados no dan cuenta de la condición y clase de los soldados implicados en deserciones, pero lo que sí se puede señalar es que, entre las medidas punitivas y los dictámenes judiciales, la negación o suspensión de la ciudadanía se consideró un elemento disuasivo para contener "la deserción muy escandalosa" y fue aplicada sin mayores preámbulos, en 1821, a un grupo de desertores por la Comandancia General en Línea ubicada en Puerto Cabello. A todos los implicados se les suspendió la condición de ciudadanos de la República (AGN, R., H., t. 8, f. 357).

Lo anterior permite ponderar la importancia de la ciudadanía en la construcción del Estado. En esto, el ejército fue factor constituyente de legitimación política y principal fuente de la representación política, permitiendo, con la participación de sus miembros en las elecciones, acercarlos como ciudadanos a las decisiones gubernamentales. A mediados de 1818, en Angostura, se creó una municipalidad de elección popular por tiempo definido de un año con la facultad de nombrar los empleados municipales y el alcalde (Vergara y Velasco, 1897, p. 40). Durante las elecciones para seleccionar los 
representantes al Congreso General de Colombia que se reunió en la Villa del Rosario de Cúcuta en 1821, los soldados participaron con su voto al lado de ciudadanos honorables y poderosos (Almarza, 2016, pp. 75-110). Es difícil ocultar la tensión generada, desde entonces, entre militares y civiles, dado que el estatus inferior de la mayor parte del ejército era significativo, lo cual sirve, además, para entender su permanente subordinación (Maignot, 1969, pp. 297-355).

¿Qué papel jugaron los soldados libertos en medio de esas tensiones? La respuesta no admite ambigüedades: obedecer las órdenes de sus superiores. Sin embargo, luego de cumplir el tiempo de servicio militar estipulado por ley, se convirtieron en ciudadanos comunes y corrientes, pero lo más seguro fue su regreso a las labranzas, vaquería, minería, zapatería, herrería o, como Silvestre, el exesclavo de Francisco Martín Yanes: una persona libre asalariada vendiendo en una tienda pública $\mathbf{C}$

\section{Referencias}

Almarza, Á. (2016). Representación política y prácticas electorales en los albores de la República de Colombia: el caso de la Provincia de Guayana, 1820-1821. Claves, Revista de Historia, 2, 75-110. DOI: 10.25032/crh.v2i2.46

Blanchard, P. (2002). The Language of Liberation: Slave Voice in the Waes of Independence. Hispanic American Historical Review, 82(3), 499-523. DOI: 10.1215/00182168-82-3-499

Bolívar, S. (2009). Bolívar a Santander, San Carlos, 13 de junio de 1821. En Doctrina del Libertador (pp. 184-186). Caracas: Biblioteca Ayacucho.

Carrera, G. (1972). Boves. Aspectos socioeconómicos de la guerra de Independencia. Caracas: Universidad Central de Venezuela.

Clavijo, H. (1989). Reformas fiscales y crisis política del régimen colonial de la Nueva Granada, 1770. Estudio de caso. Anuario Colombiano de Historia Social y de la Cultura, 16-17, 49-77. Recuperado de https://revistas.unal.edu.co/index.php/achsc/article/ view/36095

Conde, J. (2009). Buscando la nación. Ciudadanía, clase y tensión racial en el Caribe colombiano. 1821-1853. Medellín: La Carreta Editores/Universidad del Atlántico.

Conde, J. (2011). El general José Padilla: entre el heroísmo naval y la acción política. En: A. Abello Vives (ed.), Cuadernos de la Expedición Padilla (pp. 21-27). Cartagena: Unitecnológica. 
Conde, J. (abril, 2017). La Constitución es el remedio legal. La ley, el ciudadano y el Estado en la República de Colombia 1821-1830. Trabajo presentado en I Coloquio sobre Ciudadanía: Entre libertades y derechos, perspectivas históricas de la ciudadanía en Colombia, Medellín, Colombia.

Cuerpo de leyes de la República de Colombia. (1840). Caracas: Imprenta de Valentín Espinal.

Dubois, L. (2000). Citizenship through assimilation and through autonomy: Guadeloupe, 1792-1802. Revista Mexicana del Caribe, 10, 90-106. Recuperado de http://recaribe. uqroo.mx/numeros/anteriores/10/102dubois.pdf

Dubois, L. (2003). «Citoyens et amis!» Esclavage, citoyennetè et Rèpublique dans les Antilles françaises à l'èpoque rèvolutionnaire. Annales Histoire, Sciences Sociales, 58(2), 281303. Recuperado de https://www.cairn.info/revue-annales-2003-2-page-281.htm. DOI: 10.224003/UQROOMX/RMC10/02

Echeverri, M. (2009). Los derechos de indios y esclavos realistas y la transformación política en Popayán, Nueva Granada (1808-1820). Revista de Indias, 69(246), 45-72. DOI: 10.3989/revindias.2009.012

Ejército de Vanguardia. (1969). Cuartel General en La Laguna, a 17 de marzo de 1819. En Libro de Órdenes Generales del Ejército de Operaciones de la Nueva Granada, de que es Comandante en Jefe el General de Brigada Ciudadano Francisco de Paula Santander 1819 (pp. 11-12). Bogotá: Banco Cafetero.

Espinosa, J. (1932). Memorias de un abanderado. Bogotá: Minerva.

Frega, A. (2010). "La patria me hizo libre". Aproximación a la condición de los esclavos durante las Guerras de Independencia en la Banda Oriental. En S. Mallo e I. Telesca (eds.), "Negros de la patria". Los afrodescendientes en las luchas por la Independencia en el antiguo virreinato del Río de la Plata (pp. 171-186). Buenos Aires: SB.

Gómez, A. y Morelli, F. (Eds.), (2013). L'Atlantique Révolutionarire. Une Perspective IbéroAméricaine. Paris: Les Perséides.

Izecksohn, V. (2010). Deportação ou integração. Os dilemas negros de Lincoln. Topoi, 11(20), 55-74. DOI: 10.1590/2237-101X011020005

Maignot, A. (1969). Social structure, social status, and civil-military conflict in urban Colombia, 1810-1851. En S. Thernstrom y R. Sennett (eds.), Nineteenth-Century Cities. Essays in the New Urban History (pp. 297-355). New Haven: Yale University Press.

Mier, J. (1981). La Gran Colombia. Decretos de la Secretaría de Estado y del Interior, 1821-1824 (Tomo 1). Bogotá: Presidencia de la República.

Morelli, F. (2016). Guerras, libertad y ciudadanía. Los afro-descendientes de Esmeraldas en la Independencia. Revista de Indias, 76(266), 83-108. DOI: 10.3989/revindias.2016.003

Pita, R. (2012). El reclutamiento de negros esclavos durante las guerras de independencia de Colombia, 1810-1825. Bogotá: Academia Colombiana de Historia. 
Prado, L. (2014). El consenso trastocado: esclavismo y sedición en las cuadrillas mineras del Pacífico. Popayán 1810-1840. Reflexión Política, 16(32), 142-156. DOI: $10.29375 / 01240781.2144$

Rabinovich, A. (2013). Ser soldado en las Guerras de Independencia. Buenos Aires: Sudamericana.

Restrepo, J. (1858). Historia de la Revolución de la República de Colombia en la América Meridional (Tomo 1). Paris: Besanzon.

Restrepo, J. (1954). Diario político y militar (Tomo 1). Bogotá: Imprenta Nacional.

Rosanvallon, P. (1999). La consagración del ciudadano. México: Instituto Mora.

Rossigno, M. (2013). A 'Black Declaration of Independence'? War, Republic, and Race in the United States of América, 1775-1787. En P. Serna, A. De Francesco y J. Miller (eds.), Republics at War, 1776-1840. Revolutions, Conflicts, and Geopolitics in Europe and the Atlantic World (pp. 107-130). Houndmills: Palgrave Macmillan.

Schama, S. (1990). Ciudadanos. Crónica de la Revolución Francesa. Buenos Aires: Javier Vergara.

Schwartz, S. (1992). Slaves, Peasants and Rebels. Reconsidering Brazilian Slavery. Chicago: University of Illinois Press.

Serna, P., De Francesco, A. y Miller, J. (Eds.), (2013). Republics at War, 1776-1840. Revolutions, Conflicts, and Geopolitics in Europe and the Atlantic World. Houndmills: Palgrave Macmillan.

Silva, L. (2015). Afrodescendentes livres e libertos e igualdade política na América portuguesa. Mudança de status, escravidão e perspectiva atlântica (1750-1840). Almanack Guarulhos, 11, 571-632. DOI: 10.1590/2236-463320151102

Starobinski, J. (1964). La invención de la libertad 1700-1789. Barcelona: Carrogio.

Thibaud, C. (2003). Repúblicas en armas. Los ejércitos bolivarianos en la guerra de Independencia en Colombia y Venezuela. Bogotá: Planeta/IFEA.

Tovar, H. (1994). Convocatoria al poder del número. Bogotá: Archivo General de la Nación.

Vergara, A. (2011). Las armas a cambio de la libertad. Los esclavos en la guerra de independencia de Venezuela (1812-1835). Relaciones, 32(127), 47-85. DOI: 10.24901/ rehs.v32i127.554

Vergara y Velasco, F. J. (1897). 1818 (Guerra de Independencia). Bogotá: Imprenta Nacional.

\section{Archivo}

Archivo General de la Nación (AGN), Asuntos Criminales, tt. 29, 84.

Archivo General de la Nación (AGN), Fondo Enrique Ortega Ricaurte, caja 193.

Archivo General de la Nación (AGN), Peticiones y Solicitudes, tt. 1, 3, 5, 6, 8, 11, 15, 16.

Archivo General de la Nación (AGN), República, Historia, tt. 2, 3, 7, 8. 